\title{
Autoimmune lymphoproliferative syndrome
}

INSERM

\section{Source}

INSERM. (1999). Orphanet: an online rare disease and orphan drug data base. Autoimmune lymphoproliferative syndrome. ORPHA:3261

Autoimmune lymphoproliferative syndrome (ALPS) is a rare, inherited disorder

characterized by non-malignant lymphoproliferation, multilineage cytopenias, and a lifelong increased risk of Hodgkin's and non-Hodgkin's lymphoma. 